\title{
A CONCEPÇÃO DE PERSONAGEM DE ANTONIO CANDIDO: PRESSUPOSTOS E IMPLICAÇÕES
}

\author{
Elvis Paulo Couto
}

Submetido em 21 de maio de 2019.

Aceito para publicação em 23 de julho de 2019.

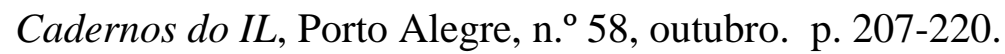

\section{POLÍTICA DE DIREITO AUTORAL}

Autores que publicam nesta revista concordam com os seguintes termos:

(a) Os autores mantêm os direitos autorais e concedem à revista o direito de primeira publicação, com o trabalho simultaneamente licenciado sob a Creative Commons Attribution License, permitindo o compartilhamento do trabalho com reconhecimento da autoria do trabalho e publicação inicial nesta revista.

(b) Os autores têm autorização para assumir contratos adicionais separadamente, para distribuição não exclusiva da versão do trabalho publicada nesta revista (ex.: publicar em repositório institucional ou como capítulo de livro), com reconhecimento de autoria e publicação inicial nesta revista.

(c) Os autores têm permissão e são estimulados a publicar e distribuir seu trabalho online (ex.: em repositórios institucionais ou na sua página pessoal) a qualquer ponto antes ou durante o processo editorial, já que isso pode gerar alterações produtivas, bem como aumentar o impacto e a citação do trabalho publicado.

(d) Os autores estão conscientes de que a revista não se responsabiliza pela solicitação ou pelo pagamento de direitos autorais referentes às imagens incorporadas ao artigo. A obtenção de autorização para a publicação de imagens, de autoria do próprio autor do artigo ou de terceiros, é de responsabilidade do autor. Por esta razão, para todos os artigos que contenham imagens, o autor deve ter uma autorização do uso da imagem, sem qualquer ônus financeiro para os Cadernos do IL.

\section{POLÍTICA DE ACESSO LIVRE}

Esta revista oferece acesso livre imediato ao seu conteúdo, seguindo o princípio de que disponibilizar gratuitamente o conhecimento científico ao público proporciona sua democratização.

http://seer.ufrgs.br/cadernosdoil/index

Segunda-feira, 07 de outubro de 2019. 


\title{
A CONCEPÇÃO DE PERSONAGEM DE ANTONIO CANDIDO: PRESSUPOSTOS E IMPLICAÇÕES
}

\section{ANTONIO CANDIDO'S CONCEPTION OF CHARACTER: ASSUMPTIONS AND IMPLICATIONS}

\author{
Elvis Paulo Couto
}

\begin{abstract}
RESUMO: Este artigo investiga o texto "A personagem do romance" (1963), de Antonio Candido, a fim de inferir a concepção que o autor nele apresenta de personagem. Nosso objetivo é demonstrar que a caracterização dessa categoria da narrativa se baseia nos seguintes pressupostos: 1) na complementaridade entre literatura e sociologia, pois ambas fornecem conhecimentos diferentes sobre o mesmo objeto; 2) na ideia de que o processo de construção da personagem relaciona-se com a elaboração da etnografia, uma vez que, nos dois casos, busca-se desvendar a alteridade. Por fim, mostramos que a tipologia das personagens do romance implica a peculiaridade da crítica literária de Candido.
\end{abstract}

PALAVRAS-CHAVE: Antonio Candido; personagem; romance; sociologia.

ABSTRACT: This article investigates the text "A personagem do romance” (1963), by Antonio Candido, in order to infer the conception that the author in it presents of character. Our objective is to demonstrate that the characterization of this category of narrative is based on the following assumptions: 1) in the complementarity between literature and sociology, as both provide different knowledge about the same object; 2) in the idea that the process of construction of the character is related to the elaboration of ethnography, since in both cases one seeks unveil the otherness. Finally, we show that the character typology of the novel implies the peculiarity of Candido's literary criticism.

KEYWORDS: Antonio Candido; character; novel; sociology.

\section{Introdução}

Antonio Candido iniciou a carreira de crítico literário em 1941, quando ainda era estudante de Ciências Sociais na Universidade de São Paulo. Naquele momento, seus primeiros trabalhos de análise de obras de literatura foram publicados na revista Clima, "da qual também faziam parte o crítico de cinema Paulo Emílio Salles Gomes, o dramaturgo Alfredo Mesquita, o crítico de teatro Décio de Almeida Prado e a professora de estética e crítica de arte Gilda de Mello e Souza" (OCUPAÇÃO Antonio Candido, 2018, p. 85). Entre 1943 e 1947, Candido trabalhou para os jornais Folha da Manhã e Diário de São Paulo, exercendo a assim chamada crítica de rodapé. Na função de crítico de jornal, era responsável por avaliar textos inéditos, tendo a oportunidade de julgar livros de estreia como Perto do coração selvagem, de Clarice Lispector, e Pedra do sono, de João Cabral de Melo Neto.

\footnotetext{
* Mestrando do Programa de Pós-Graduação em Estudos Literários da Faculdade de Ciências e Letras da Universidade Estadual Paulista "Júlio de Mesquita Filho", UNESP.
} 
Segundo Roberto Schwarz (1987, p. 129), foi somente em 1970 que Candido publicou, na Revista do Instituto de Estudos Brasileiros, "o primeiro estudo literário propriamente dialético", qual seja, a "Dialética da malandragem". Esse ensaio de interpretação das Memórias de um sargento de milícias, de Manuel Antônio de Almeida, insere-se, para Schwarz, no âmbito da crítica marxista. Outro trabalho influenciado pelo marxismo, fruto da "necessidade do trânsito entre análise estética e reflexão histórico-social, um vaivém de esquerda", seria "De cortiço a cortiço", uma análise do romance $O$ cortiço, de Aluísio Azevedo, que foi publicada integralmente em 1991, na revista Novos Estudos CEBRAP. (SCHWARZ, 1992, p. 31, grifos do autor).

Embora tenham inspiração nas obras de Marx, como salientou Schwarz, os ensaios aos quais nos referimos parecem conter pressupostos sociológicos e antropológicos. Mais do que isso: o método de crítica literária empregado por Candido não é exclusivamente marxista, ele é explicável também por meio da concepção, por assim dizer, socioantropológica do autor. Essa é a nossa primeira hipótese.

É bom frisar que já se falou sobre a presença da antropologia nos estudos literários de Candido. Luiz Costa Lima (1992, p. 163-164) demonstrou que o conceito de sistema na Formação da literatura brasileira alinha-se à antropologia social inglesa, pois a ideia de que as manifestações literárias tornam-se de fato literatura quando se integram à vida social se coaduna com o funcionalismo de Evans-Pritchard e RadcliffeBrown.

Nossa segunda hipótese é a seguinte: o texto de teoria literária "A personagem do romance", publicado pela primeira vez, conforme atesta Vinicius Dantas (2002, p. 35), em 1963 no "Boletim $n^{\circ}$ 284, Teoria Literária e Literatura Comparada $n^{o}$ 2", revela aspectos significativos do método crítico que sustém os ensaios "Dialética da malandragem" e "De cortiço a cortiço", bem como pode esclarecer de que maneira, na visão de Candido, a literatura e a sociedade relacionam-se.

\section{Literatura e sociologia: pontos de convergência}

Como pode um romance transpor para o universo limitado da linguagem escrita os aspectos de uma determinada sociedade? Dar resposta a essa pergunta não é algo fácil, mas foi o que fez Antonio Candido ao longo de sua trajetória intelectual. Isso é o que demonstram as suas obras, tanto as de teoria e crítica literária como as duas teses universitárias. $O$ método crítico de Sílvio Romero atém-se às relações que o polímata da Escola de Recife estabeleceu entre literatura e formação cultural, ao passo que $O s$ parceiros do Rio Bonito nasceudo desejo que o autor tinha de analisar a poesia popular dos caipiras paulistas - o cururu.

Em 2017, as filhas de Candido - Ana Luísa Escorel, Laura de Mello e Souza e Marina de Mello e Souza - decidiram doar o acerco pessoal do autor ao Instituto de Estudos Brasileiros da Universidade de São Paulo (IEB/USP). O Instituto Itaú Cultural encarregou-se de recolher o material bibliográfico, reorganizá-lo e torná-lo público, processo este que terminará somente em 2019. Todavia, já se pode ter acesso a alguns manuscritos e datiloscritos publicados em catálogo pela Ocupação Antonio Candido (2018) - primeira ação cultural com vistas à exposição da documentação inédita, fotografias e objetos do crítico literário.

Um dos cadernos do autor, fotocopiado no referido catálogo intitula-se " $O$ grupo social e sua manifestação no plano literário". Nele, pode-se perceber a insatisfação de 
Candido (2018b, p. 29) no que diz respeito aos estudos da relação entre literatura e sociedade: "O estudo das relações entre as manifestações literárias e a vida social se acha quase sempre obscurecido por uma série de formulações insatisfatórias." Podemos tomar como exemplo dessa afirmação a obra de dois historiadores da literatura, um francês e um brasileiro: Hippolyte Taine e Sílvio Romero. Ambos fizeram parte da formação de Candido e são autores cujas noções de crítica cultural eram coerentes com o momento histórico em que viviam: o positivismo estava em voga no século XIX e o apogeu do rigor científico em matéria de análise literária era conceber a obra como resultante das condições externas. Mas esse método começou a cair em desuso em meados do século XX, quando estudiosos de países europeus tiveram conhecimento das proposições dos formalistas russos, que mostraram a inviabilidade das explicações que desconsideram o valor da forma, isto é, do material linguístico esteticamente elaborado. No caso do gênero romanesco, um dos equívocos da interpretação seria desprezar o modo como estão construídos o narrador, a ação, o espaço, o tempo e as personagens.

Todos os ensaios de Antonio Candido comprovam que ele rejeitou tanto a investigação puramente formal como a que procura analisar a obra tendo em vista apenas o mundo exterior. Procurou, em contrapartida, formular um método próprio, capaz de integrar obra literária e realidade social. Vejamos um trecho do ensaio "Crítica e sociologia (tentativa de esclarecimento)", no qual há a elucidação, ainda que de modo sintético, desse método:

Quando fazemos uma análise deste tipo [esboço de análise do romance Senhora, de José de Alencar], podemos dizer que levamos em conta o elemento social, não exteriormente, como referência que permite identificar, na matéria do livro, a expressão de uma certa época ou de uma sociedade determinada; nem como enquadramento, que permite situá-lo historicamente; mas como fator da própria construção artística, estudado no nível explicativo e não ilustrativo. (CANDIDO, 1975, p. 7).

Candido toma como exemplo uma obra na qual os aspectos sociais representados não são apenas o tema, são antes componentes da "construção artística", isto é, da estrutura. Caberia a determinadas produções literárias, portanto, interpretações que verifiquem como os fatores externos são internalizados. O romance Senhora é exemplar nesse sentido, pois nele a heroína Aurélia Camargo, "tocada pela desumanização capitalista", reduz a personagem Fernando Seixas a uma mercadoria sujeita ao mecanismo de compra e venda. O caráter mercadológico do relacionamento amoroso não é representado na história, apenas no conteúdo do livro, mas nas "próprias imagens do estilo", "na própria composição do todo e das partes" (CANDIDO, 1975, p. 6-7).

Note-se que, segundo o esquema proposto, a sociologia não inviabiliza a crítica literária, podendo auxiliá-la ou mesmo embasá-la. Isso condiz com a evolução do pensamento de Candido, marcada, como mostram os manuscritos que deram origem aos textos de Literatura e sociedade, pela

[...] recusa de optar entre sociologia e literatura pelo sentimento de quanto se completam na construção de uma visão do homem: recusa de optar entre sensibilidade e investigação: donde consequência necessária o estudo dos pontos de contacto da sociedade com a criação literária; a sociologia da literatura. (CANDIDO, 2018b, p. 67). 
Se, para alguns, a ciência e a arte não são complementares, para Candido - que exerceu ao mesmo tempo a crítica literária e o ensino da sociologia - são duas formas de conhecimento do homem que podem iluminar-se mutuamente. Os objetos de estudo da sociologia são os fatos sociais, que, segundo Durkheim $(1978$, p. 3), "consistem em maneiras de agir, de pensar e de sentir exteriores ao indivíduo, dotadas de um poder de coerção em virtude do qual se lhe impõem." De acordo com essa definição clássica, a ação individual não é puramente autônoma, mas coagida por forças exteriores. Durkheim (1978, p. 3) não nega a liberdade individual, porém, ressalta que as "nossas ideias e tendências não são elaboradas por nós, mas nos vêm de fora".

Candido ocupou durante dezesseis anos a cadeira de Assistente II de Sociologia na antiga Faculdade de Filosofia, Ciências e Letras da USP. Entre 1942 e 1958, esteve diretamente ligado a Fernando de Azevedo, o chefe do Departamento de Sociologia e Antropologia, cuja produção científica filiava-se "à influência de Durkheim" (CANDIDO, 2006, p. 284). É provável que Candido tenha incorporado à sua concepção de literatura algo da sociologia durkheimiana, segundo a qual a linguagem - e no universo dela se inclui a arte literária - é uma instituição social e, portanto, apesar de poder ser moldada conforme a criatividade do indivíduo, não pode abdicar de leis sociais que regem o seu funcionamento. Assim sendo, a literatura seria uma forma de conhecimento da sociedade, um instrumento de grande valia à investigação sociológica.

\section{A concepção antropológica de personagem}

Antonio Candido afirmou, numa entrevista concedida em 2014: "A literatura é uma necessidade universal, experimentada em todas as sociedades, desde as que chamamos primitivas às mais avançadas; o homem tem necessidade de efabular." (Candido, 2014). Para o autor, não existe, por conseguinte, sociedade sem literatura. Certamente, o oposto também se confirma: não existe literatura sem sociedade, pois a fabulação provém da vontade que certos homens têm de criar códigos linguísticos capazes de expressar esteticamente valores, sentimentos e modos de existência construídos interpessoalmente. Em "A personagem do romance", Candido discorre sobre o processo de construção da personagem. Esse vocábulo tem origem no termo latino persona, que significa tanto pessoa como máscara utilizada pelos atores gregos e romanos. Não há dúvida de que a fonte de invenção da personagem é a pessoa, ou as pessoas, tendo em vista que frequentemente os escritores configuram as personagens a partir da reunião de traços físicos e comportamentais provenientes de um ou vários indivíduos. Nas palavras de Candido (2007a, p. 55): “o romance se baseia, antes de mais nada, num certo tipo de relação entre o ser vivo e o ser fictício, manifestada através da personagem, que é a concretização deste."

A composição da personagem está intimamente ligada à tentativa de representar o ser de papel como se fosse o ser real. Para isso, o escritor precisa servir-se de certo conhecimento sobre esse último, o que constitui de antemão um problema.

Quando abordamos o conhecimento direto das pessoas, um dos dados fundamentais do problema é o contraste entre a continuidade relativa da percepção física [...] e a descontinuidade da percepção, digamos, espiritual, que parece frequentemente romper a unidade antes apreendida. (CANDIDO, 2007a, p. 55, grifos do autor). 
Candido toma o seguinte problema antropológico: como podemos conhecer o outro? Não é possível fazê-lo integralmente, pois a psicologia do indivíduo é um domínio vasto do qual podem brotar infinitos modos de agir. "Daí concluirmos que a noção a respeito de um ser, elaborada por outro ser, é sempre incompleta, em relação à percepção física inicial. E que o conhecimento dos seres é fragmentário." (CANDIDO, 2007a, p. 56, grifo do autor). Desse modo, como é possível lograr um conhecimento razoável do homem que dê certa unidade aos "fragmentos de ser, que nos são dados por uma conversa, um ato, uma sequência de atos, uma afirmação, uma informação"? (CANDIDO, 2007a, p. 56). Candido (2007a, p. 58) nos diz que a construção da personagem do romance envolve essa tentativa de unificar a fragmentação humana.

A partir dessas asserções, um pressuposto básico pode ser identificado: a antropologia, desde os seus primórdios, quando almejava caracterizar as, assim chamadas, sociedades primitivas, e depois, quando se abre à possibilidade de entender 0 comportamento humano na cena urbana, sempre teve como foco o desvendamento da alteridade. Esse objetivo vai ao encontro da técnica literária de criação das personagens, as quais também são capazes de revelar noções sobre os aspectos psíquicos do ser.

O processo de configuração das personagens descrito por Candido aproxima-se da atividade de análise realizada pelo antropólogo ante o grupo social que é objeto de sua pesquisa.

Na vida, estabelecemos uma interpretação de cada pessoa, a fim de podermos conferir certa unidade à sua diversificação essencial, à sucessão dos seus modos-de-ser. No romance, o escritor estabelece algo mais coeso, menos variável, que é a lógica da personagem. (CANDIDO, 2007a, p. 58-59).

Esse trecho exprime uma concepção antropológica de personagem. Por meio da linguagem escrita, o antropólogo e o escritor buscam atribuir certa coesão à complexidade de "modos-de-ser" que constitui a experiência da vida em sociedade. Fazem-no por caminhos diversos, embora amiúde cheguem ao mesmo propósito: aquele capta os elementos da cultura de certo grupo para formular uma generalização, isto é, uma espécie de indivíduo modelar que não existe na realidade, mas constitui-se como tipo social capaz de fornecer conhecimento empírico, ao passo que este, por meio da percepção de diversos atributos físicos e psicológicos, de variados aspectos das relações sociais, modela seres fictícios, porém, nascidos de circunstâncias objetivas. Tanto o romancista como o etnógrafo reduzem a um conjunto limitado de palavras o pluralismo e a inconstância da conduta humana. $\mathrm{O}$ primeiro busca a lógica da pessoa imaginada a partir de caracteres reais, enquanto o segundo, através da observação da vida em grupo, extrai um padrão de pessoa, ou seja, confere lógica à maneira de ser desordenada.

$\mathrm{Na}$ verdade, a escrita da etnografia - a descrição da cultura de certo agrupamento humano - e a escrita do romance, são modos de dominar a profusão caótica das ações desempenhadas pelo ser. Todavia, se o etnógrafo deseja que o produto de seu trabalho seja considerado científico, o romancista não tem essa pretensão ao apresentar o fruto de seu ofício como literatura, isto é, como ficção. Malgrado não almejar a objetividade científica, o escritor promove aquilo que Candido (2007a, p. 59) chama "simplificação estrutural", que pode ser aproximado do exercício antropológico de apreensão dos "modos-de-ser" por meio da reunião das características físicas ou relativas à personalidade. Nos termos de Clifford Geertz: 
Fazer a etnografia é como tentar ler (no sentido de "construir uma leitura de") um manuscrito estranho, desbotado, cheio de elipses, incoerências, emendas suspeitas e comentários tendenciosos, escritos não com os sinais convencionais do som, mas com exemplos transitórios de comportamento modelado. (GEERTZ, 2008, p. 20).

Portanto, compõe-se uma personagem ou descreve-se uma cultura quando se isolam da totalidade abstrusa certos traços físicos e psicológicos.

Sabe-se que Malinowski revolucionou as bases da antropologia moderna. Criador do método conhecido como observação participante, compôs a etnografia dos trobriandeses não através de dados coletados por viajantes e informantes, mas por meio de sua infiltração prolongada na cultura dos povos da Nova Guiné. Assim, pôde conviver diariamente com os nativos e registrar as relações sociais por eles firmadas, de modo a arquitetar paulatinamente, por meio da escrita, a totalidade da cultura autóctone. Observe-se o que Malinowski diz a respeito da etnografia:

Sem dúvida, para que um trabalho etnográfico seja válido, é imprescindível que cubra a totalidade de todos os aspectos - social, cultural e psicológico — da comunidade; pois esses aspectos são de tal forma interdependentes que um não pode ser estudado e entendido a não ser levando-se em consideração todos os demais. (MALINOWSKI, 1978, p. 11-12).

Segundo Malinowski, a etnografia é o material linguístico que condensa a totalidade da vida social de um determinado grupo. Analogamente, o criador do romance incumbe-se de abstrair e combinar certos elementos corpóreos e emocionais de um ou vários seres para compor a personagem, despertando no leitor, desse modo, a sensação de totalidade da pessoa representada. Segundo James Clifford, tanto o romance realista como a etnografia operam por meio da "sinédoque", ou seja, os fragmentos são concebidos como "microcosmos ou analogias do todo" (CLIFFORD, 2008 , p. 29). Mas que são esses fragmentos? No caso do trabalho etnográfico, são as percepções difusas do antropólogo acerca das ações das pessoas, das noções de temporalidade e de espacialidade que elas têm. Já no caso do romancista, trata-se da construção das personagens e das demais categorias da narrativa (narrador, focalização, história, espaço, tempo, etc.) através da combinação criativa de diversos aspectos intuídos da realidade.

Isso posto, podemos dizer que a invenção da personagem e a descrição do grupo social estão relacionadas à atividade de abstração e condensação de aspectos dos seres. Em ambos os casos, a imaginação do observador (escritor ou etnógrafo) é fundamental. Portanto, a relação entre o ser real e o ser de papel - ou mesmo entre a literatura e a etnografia - não pode ser totalmente desconsiderada, sobretudo, após os estudos de Clifford Geertz (2008) que vê a etnografia como interpretação da cultura, isto é, como meio de transformação dos comportamentos e das instituições sociais em discurso. $\mathrm{O}$ autor desconstruiu a ideia de que a antropologia é a ciência capaz de revelar a verdade das culturas, propondo, ao invés disso, algo mais modesto: "o objetivo da antropologia é o alargamento do universo do discurso humano" (GEERTZ, 2008, p. 24). 


\title{
4 Os tipos de personagem e a coerência da crítica
}

Candido recorre ao pensador inglês setecentista Samuel Johnson para fazer a seguinte classificação:

\begin{abstract}
As personagens de costumes são muito divertidas; mas podem ser mais bem compreendidas por um observador superficial do que as de natureza, nas quais é preciso ser capaz de mergulhar nos recessos do coração humano. (JOHNSON apud CANDIDO, 2007a, p. 61).
\end{abstract}

Essa distinção é fundamental para caracterizar a crítica literária de Candido, pois a tipologia das personagens é um dos fatores que determinam a especificidade da interpretação. Atualizando o pensamento de Johnson, Candido afirma o seguinte:

[...] o romancista "de costumes" vê o homem pelo seu comportamento em sociedade, pelo tecido das suas relações e pela visão normal que temos do próximo. Já o romancista de "natureza" o vê à luz da sua existência profunda, que não se patenteia à observação corrente, nem se explica pelo mecanismo das relações. (CANDIDO, 2007a, p. 62).

Para constituir a "personagem de costumes", o romancista compõe uma figura representativa de determinado grupo social. Daí a conhecida personagem-tipo, cujos traços prototípicos reproduzem a "visão normal" que temos da classe a que ela pertence ou da profissão que exerce. Quando um romance é estruturado a partir desse tipo de personagem, a crítica que se lhe adéqua, embora não seja a única viável, é a sociologicamente orientada, haja vista que a sociologia se interessa pelas camadas e classes sociais.

Isso explica, parcialmente, a adoção do ponto de vista histórico-sociológico no ensaio "Dialética da malandragem". Nesse texto, que consiste numa crítica ao romance Memórias de um sargento de milícias, Candido (1993b, p. 28) diz que Manuel Antônio de Almeida extraiu "dos fatos e das pessoas um certo elemento de generalidade", bem como reduziu "os fatos e os indivíduos a situações e tipos gerais". Os fatos e as situações são a conjuntura política, social e cultural do Brasil colonial, mais propriamente, do Rio de Janeiro de D. João VI, conforme representados na obra. Já as pessoas e os indivíduos são, em sua maioria, as gentes livres não proprietárias, aquelas que não possuem cabedal nem são escravas. O autor depreendeu de circunstâncias objetivas e particulares noções gerais que lhe permitiram imaginar a intriga e as personagens de seu romance.

No ensaio "De cortiço a cortiço", Candido (1993a, p. 138) diz que, no romance $O$ cortiço de Aluísio Azevedo, a coletividade "exprime a generalidade do social." Aqui, temos novamente uma obra literária em que são proeminentes as "personagens de costumes". Desprovidas de profundidade psicológica e representativas da classe dos trabalhadores explorados, essas personagens, apesar de determinadas características próprias, são generalizações feitas pelo escritor através da estrutura da obra e, assim sendo, além de um exercício artístico, são o resultado de uma sensibilidade sociológica aflorada.

Os paladinos do formalismo poderiam contestar essa complementaridade entre literatura e sociologia, alegando que essa se restringe ao mundo concreto e aquela ao domínio da criatividade. Mas o objeto da sociologia - a sociedade — é algo concreto?. Se pensássemos de maneira elementar, diríamos que sim, mas certamente essa 
afirmação derivaria de uma concepção equivocada, segundo a qual a sociedade é apenas a junção dos indivíduos. Durkheim mostrou que o conceito de sociedade envolve certo grau de abstração:

\begin{abstract}
As consciências particulares, unindo-se, agindo e reagindo umas sobre as outras, fundindo-se, dão origem a uma realidade nova que é a consciência da sociedade. A mentalidade dos grupos não é a dos seres particulares, precisamente porque a primeira pressupõe uma pluralidade de espíritos particulares, combinados entre si. Uma coletividade tem as suas formas específicas de pensar e de sentir, às quais os seus membros se sujeitam, mas que diferem daquelas que eles praticariam se fossem abandonados a si mesmos. (DURKHEIM, 1975, p. 117).
\end{abstract}

A consciência social é exterior aos indivíduos e autônoma; trata-se de uma força coercitiva que nos impõe uma série de regras e de "modos-de-ser". Para que a captemos, é necessária certa capacidade de presumir a origem das práticas nascidas do contato entre as pessoas. Interessa à sociologia, portanto, não o indivíduo isolado, mas tudo o que diz respeito às relações sociais, sobretudo, as leis e os costumes que delas decorrem. Desse modo, as Memórias de um sargento de milícias oferecem ao leitor conhecimento sobre a sociedade, porque são um romance que, de acordo com Candido (2007b, p. 531), ao invés de enfocar "a dinâmica do espírito", "atém-se à vida de relação", ou seja, engendra uma pesquisa estética da sociedade, lida de maneira não científica com o objeto da sociologia.

$\mathrm{Na}$ Formação da literatura brasileira, Candido nos mostra que os "tipos" das Memórias referem-se menos a pessoas do que a classes sociais:

[...] o autor procura dissolvê-los numa categoria geral, mais social do que psicológica, substituindo a própria indicação do nome pela do lugar que têm no grupo, a profissão, a função: o "compadre", a "comadre", o "tomalargura", o "Mestre de Cerimônias", os "primos", as duas "velhas", a "cigana", o "tenente-coronel", o "fidalgo" - que através de todo o livro não conhecemos doutra forma. (CANDIDO, 2007b, p. 533).

Candido (2007b, p. 534) afirma ainda sobre as Memórias: "Os seus personagenstipos são mais sociais do que psicológicos, definindo antes um modo de existir do que de ser." Parece-nos que as personagens-tipo do romance de Manuel Antônio de Almeida são veículos para que se represente a maneira como estavam arranjados os grupos sociais no início do século XIX e como a moral rígida e a moral débil conviviam sem grandes conflitos. Na verdade, essas personagens superficiais e sem grandeza de espírito permitem a escrita de uma espécie de crônica do "tempo do rei" que depende menos da intuição psicológica do autor do que da sociológica.

Daí a composição do livro estar subordinada à lógica do acontecimento, que por sua vez obedece ao movimento mais amplo do panorama social. O que encontramos no fundo do romance é essa condição, de ordem sociológica. (CANDIDO, 2007b, p. 534).

Se a "condição" do livro é "de ordem sociológica", a crítica que se propõe a ser coerente com a natureza dele deve lançar mão de explicações também elas sociológicas. E isso foi o que fez Candido na "Dialética da malandragem" ao evidenciar que uma obra considerada mediana no conjunto da ficção brasileira, quando recebe a iluminação 
adequada - no caso, a histórico-sociológica - pode passar a figurar entre as maiores de seu tempo. Portanto, a presença das "personagens de costumes" é um indício de que a força do romance reside naquilo que Candido chama "vida de relação".

A crítica psicológica, nesse caso, encontraria dificuldades para se legitimar, dada a superficialidade espiritual das "personagens de costumes", as quais são habilitadas a revelar atributos da mentalidade social. As personagens a que Candido (2007a, p. 6263) denomina, valendo-se da terminologia de Johnson, "personagens de natureza", ou "personagens esféricas", segundo a terminologia de Forster, prestam-se melhormente à crítica psicologicamente orientada, pois "são apresentadas, além dos traços superficiais, pelo seu modo íntimo de ser, e isto impede que tenham a regularidade dos outros." Em tal caso, a análise que almeja investigar a representação da interioridade do homem encontra fundamentação apropriada para fazê-lo, pois as "personagens de natureza" geralmente são fruto de observação e mesmo de pesquisa sobre comportamento, mudança de personalidade e funcionamento da mente.

Em 1943, quando Candido (2002, p. 24) definia, na abertura da coluna de crítica literária do jornal Folha da Manhã, o que ele entendia por crítica, já se podia notar que, para ele, a atividade do crítico deveria descortinar a especificidade da obra, o que ela tem de singular. $O$ trabalho de interpretação literária não poderia prescindir da "penetração": "Quero referir-me à penetração. Sem ela, sem esta capacidade, elementar para o crítico, de mergulhar na obra e intuir os seus valores próprios, não há explicação possível — isto é, não há crítica." Perceba-se que a crítica deve compreender os "valores próprios" do texto literário. Portanto, um romance em que prevaleçam as "personagens de costumes" pode ser mais bem interpretado se for priorizada a aproximação das relações sociais; no caso de um romance em que predominem as "personagens de natureza", por outro lado, a crítica coerente focalizará a representação da psicologia individual.

Para Candido, a personagem, de certa forma, define a natureza da crítica, pois, por se tratar de categoria central na narrativa, sugere a espécie do romance, bem como a intenção do autor e, assim sendo, direciona o caminho que o crítico terá de percorrer para esclarecer o significado:

[...] a natureza da personagem depende em parte da concepção que preside o romance e das intenções do romancista. Quando, por exemplo, este está interessado em traçar um panorama de costumes, a personagem dependerá provavelmente mais da sua visão dos meios que conhece, e da observação de pessoas cujo comportamento lhe parece significativo. [..] Inversamente, se está interessado menos no panorama social do que nos problemas humanos, como são vividos pelas pessoas, a personagem tenderá a avultar, complicarse, destacando-se com a sua singularidade sobre o pano de fundo social. (CANDIDO, 2007a, p. 74).

Candido, ao lado de Sérgio Milliet e Álvaro Lins, foi um dos primeiros críticos a julgar o valor do romance de estreia de Clarice Lispector. A heroína de Perto do coração selvagem, Joana, é uma "personagem de natureza", pois é psicologicamente densa, algo que se nota através da exposição das "camadas subjacentes do espírito". A descrição dos estados emocionais, nesse caso, é mais importante para que se atinja o efeito pretendido pela autora - a reflexão sobre a natureza íntima do ser — do que a construção do "pano de fundo social". A crítica seria incoerente, pois, se não se guiasse pela constituição da personagem central, se buscasse interpretar a "vida de relação" num livro em que predomina a vida interior. 
Apesar do interesse profundo que Candido tinha pela relação entre literatura e sociologia, ele escreveu, em 1944 para o jornal Folha da Manhã, um artigo sobre Perto do coração selvagem ${ }^{1}$ preservando aquilo que estamos chamando a coerência da crítica, isto é, sem fazer uso desnecessário de conhecimentos histórico-sociológicos. No lugar deles, aparecem noções acerca da composição e das tentativas de expressar o conteúdo complexo da mente. Trata-se de um exercício de desvendamento da verdade do livro:

\begin{abstract}
A Sra. Clarice Lispector aceita a provocação das coisas à sua sensibilidade, e procura recriar um mundo partindo das suas próprias emoções, da sua própria capacidade de interpretação. Para ela, [...] a meta é, evidentemente, buscar o sentido da vida, penetrar no mistério que cerca o homem. (CANDIDO, 2018a, p. 89).
\end{abstract}

Noutro excerto, Candido (2018a, p. 89, grifo do autor), ressaltando o caráter psicológico do romance e afirma: "Aos livros que tentam esclarecer mais a essência do que a existência, mais o ser do que o estar, com um tempo mais acentuadamente psicológico, talvez seja melhor chamar de aproximação. O seu campo ainda é a alma, são ainda as paixões.” Frise-se que há, aí, o alinhamento da crítica à peculiaridade da narrativa, mais propriamente, ao discurso que é responsável por fazer o leitor conhecer os sentimentos da protagonista, a sua cosmovisão e o tempo que é delimitado pela sua consciência e não pela cronologia habitual.

Para Candido, a literatura romanesca é, com a antropologia, a sociologia e a psicologia, uma forma de conhecimento do homem e da realidade que o cerca, portanto, deixa de ser ficção no sentido da falsidade para ser ficção no sentido de um depoimento profundo sobre a natureza humana e as relações sociais. $\mathrm{O}$ erro da crítica consiste, para ele, em buscar no mundo ou no ser o equivalente do mundo e do ser enquanto representação. Daí a necessidade da investigação interna: "Conclui-se, no plano crítico, que o aspecto mais importante para o estudo do romance é o que resulta da análise da sua composição, não da sua comparação com o mundo." (CANDIDO, 2007a, p. 75). É por pensar assim que Candido, ao analisar os romances Memórias de um sargento de milícias, $O$ cortiço e Perto do coração selvagem, ateve-se ao descortinamento da composição da prosa. No primeiro, a estrutura constrói o deslocamento das personagens entre os domínios da ordem e da desordem; no segundo, a alternância do comportamento espontâneo e dirigido dos grupos; no terceiro, o movimento da consciência em busca do autoconhecimento.

\title{
5 Conclusão
}

O texto "A personagem do romance" é uma teoria sobre uma das categorias mais importantes da narrativa, sem a qual é praticamente impossível que se escreva um romance. Nosso objetivo foi investigar as possíveis convergências entre essa teoria e a concepção mais geral de Antonio Candido sobre a literatura e a crítica literária.

\footnotetext{
${ }^{1}$ Utilizamos como referência a resenha intitulada "Notas de crítica literária: Perto do coração selvagem", que Antonio Candido escreveu, em 1944, para o suplemento literário do jornal Folha da Manhã. Esse texto aparece ampliado em "Uma tentativa de renovação", ensaio publicado em Brigada ligeira e outros escritos (CANDIDO, 1992). O texto originalmente composto para jornal encontra-se estendido e estilisticamente modificado em "No raiar de Clarice Lispector", um dos textos que compõem a coletânea Vários escritos (CANDIDO, 1970).
} 
Considerada a inviabilidade de analisar, aqui, todos os trabalhos de crítica do autor, concentramo-nos num texto de juventude publicado em jornal e em dois ensaios da fase de maturidade. Essa breve investigação mostrou-nos, salvo engano, que o gênero romanesco é uma expressão artística que lida, de forma não científica, com objetos também científicos, antecipando a abordagem de muitas das questões que, somente a partir do século XIX, tornaram-se matéria de pesquisa nas instituições acadêmicas.

Notamos que, para Candido, há complementaridade entre literatura e sociologia porque são dois caminhos paralelos que podem conduzir ao conhecimento do conceito algo difuso e abstrato de sociedade. Daí o possível êxito do esclarecimento mútuo entre essas esferas que parecem incompatíveis a muitos críticos literários. $\mathrm{O}$ fato de Durkheim ter demonstrado o grau de abstração que envolve a noção de consciência social permite-nos enxergar a literatura, que também implica distanciamento relativamente ao mundo objetivo, como um fenômeno que abrange tanto a disposição da psicologia individual quanto o influxo das relações sociais. Portanto, a influência de Durkheim no pensamento de Candido não se comprova somente pela presença da noção funcionalista de literatura na Formação da literatura brasileira, mas também pela consciência do autor de que a representação literária do tecido social é um modo de compreensão do objeto de pesquisa da sociologia.

A partir do texto "A personagem do romance", depreendemos que o processo de composição da personagem aproxima-se da elaboração da etnografia, pois, nos dois casos, há a atribuição de coesão e lógica, por meio da escrita, à irregularidade dos "modos-de-ser" do indivíduo. Candido parece ter uma concepção antropológica de personagem, pois a descrição que faz do procedimento de criação dessa categoria da narrativa nos remete ao exercício, empreendido pelo etnógrafo, de transposição para o universo da linguagem dos atributos que compõem a cultura de determinado grupo social. Tanto no ofício do antropólogo como no do escritor, vemos o esforço de conhecer o outro, de apreensão desse enigma chamado alteridade.

Sustentamos a ideia de que a natureza da personagem direcionou a crítica de Candido nos ensaios examinados. Ante a presença de personagens-tipo nos romances Memórias de um sargento de milícias e $O$ cortiço, o autor mobilizou conhecimentos histórico-sociológicos para esclarecer aspectos da composição, ao passo que, diante da protagonista de Perto do coração selvagem, enfatizou como o discurso tornou essa personagem psicologicamente aguda. Destaque-se que a crítica de Candido não é histórica, sociológica ou psicológica; a referência aos estudos dessas áreas serve unicamente ao propósito de decifrar aquilo a que ele originalmente denomina "fatura". Tampouco se pode dizer que "Dialética da malandragem" e "De cortiço a cortiço" são interpretações do Brasil. Na verdade, são explicações da sociabilidade brasileira representada em romances nos quais o tema do processo social é preeminente. Se insistimos na noção de coerência da crítica, foi para evidenciar que ela se baseia na análise formal, isto é, na investigação de como os fatores externos são reduzidos em estrutura literária.

Por fim, a reflexão que fizemos mostrou-nos que Candido não foi um crítico unilateral, no sentido de que sempre utilizou o mesmo método para julgar diferentes textos literários. Ao contrário, pode-se claramente notar em suas análises a abertura constante a orientações muitas vezes consideradas contraditórias. Sem empregar termos que poderiam facilmente identificá-lo com alguma corrente teórica ou ideológica, é capaz de se inspirar no marxismo, no estruturalismo, no funcionalismo, no determinismo etc., de modo a aproveitar de cada metodologia o que considera pertinente 
e evitar as explicações reducionistas. Portanto, dificilmente será possível classificar o trabalho de Candido, dada a pluralidade das referências de que se vale.

\section{REFERÊNCIAS}

ANTONIO Candido. Cedacvideos. Youtube. 6 jun. 2014. (5 min. 43s.). Disponível em: $<$ https://www.youtube.com/watch? $\mathrm{v}=4 \mathrm{cpNuVWQ} 44 \mathrm{E} \& \mathrm{t}=45 \mathrm{~s}\rangle$. Acesso em: 16 mai. 2018.

CANDIDO, Antonio. Notas de crítica literária: Perto do coração selvagem. In: OCUPAÇÃO Antonio Candido. São Paulo: Itaú Cultural, 2018a, p. 88-91.

O grupo social e sua manifestação no plano literário. In: OCUPAÇÃO Antonio Candido. São Paulo: Itaú Cultural, 2018b, p. 27-67.

A personagem do romance. In: et al. A personagem de ficção. 11. ed. São Paulo: Perspectiva, 2007a, p. 51-80.

Formação da literatura brasileira: momentos decisivos (1750-1880). 11. ed. Rio de Janeiro: Ouro sobre Azul, 2007b.

A sociologia no Brasil. Tempo Social - Revista de Sociologia da USP, São Paulo, v. 18, n. 1, p. 271-301, jun. 2006.

Notas de crítica literária: Ouverture. In: Paulo: Duas Cidades; Ed. 34, 2002, p. 23-30. Textos de intervenção. São

. De cortiço a cortiço. In: $O$ discurso e a cidade. São Paulo: Duas Cidades, 1993a, p. 123-152.

Dialética da malandragem. In: O discurso e a cidade. São Paulo: Duas Cidades, 1993b, p. 19-54.

Uma tentativa de renovação. In: . Brigada ligeira e outros escritos. São Paulo: Ed. UNESP, 1992, p. 93-102. (Coleção Biblioteca Básica).

Literatura e sociedade: estudos de teoria e história literária. 4. ed. São Paulo: Nacional, 1975.

No raiar de Clarice Lispector. In: Vários escritos. São Paulo: Duas Cidades, 1970, p. 125-131.

CLIFFORD, James. A experiência etnográfica: antropologia e literatura no século XX. Tradução: Patrícia Farias. Rio de Janeiro: Ed. UFRJ, 2008.

DANTAS, Vinicius. Bibliografia de Antonio Candido. São Paulo: Duas Cidades; Ed. 34, 2002. 
DURKHEIM, Émile. As regras do método sociológico. Tradução: Maria Isaura Pereira de Queiroz. 9. ed. São Paulo: Nacional, 1978.

A ciência social e a ação. Tradução: Inês D. Ferreira. São Paulo: Difel, 1975.

GEERTZ, Clifford. A interpretação das culturas. Tradução: Vera Ribeiro. Rio de Janeiro: LTC, 2008.

LIMA, Luiz Costa. Concepção de história literária na "Formação". In: D'INCAO, Maria Angela; SCARABÔTOLO, Eloísa Faria (Org.). Dentro do texto, dentro da vida: ensaios sobre Antonio Candido. São Paulo: Companhia das Letras; Instituto Moreira Salles, 1992, p. 153-169.

MALINOWSKI, Bronislaw Kasper. Argonautas do pacífico ocidental: um relato do empreendimento e da aventura dos nativos nos arquipélagos da Nova Guiné melanésia. Tradução: Anton P. Carr; Lígia Aparecida Cardieri Mendonça. 2. ed. São Paulo: Abril Cultural, 1978.

OCUPAÇÃO Antonio Candido. São Paulo: Itaú Cultural, 2018.

SCHWARZ, Roberto. A originalidade da crítica de Antonio Candido. Novos Estudos CEBRAP, São Paulo, n. 32, p. 31-46, mar. 1992.

Pressupostos, salvo engano, de "Dialética da malandragem". In: Que horas são? São Paulo: Companhia das Letras, 1987, p. 129-155. 